\title{
GERMINAÇÃO E QUALIDADE DE SEMENTES DE Adenostemma brasilianum (PERS.) CASS., ASTERACEAE NATIVA DE SUB-BOSQUE DE FLORESTA ATLÂNTICA $^{1}$
}

\author{
Mariana Aparecida Silva Godinho², Eveline Mantovani-Alvarenga ${ }^{3}$ e Milene Faria Vieira $^{4}$
}

\begin{abstract}
RESUMO - Foram objetivos deste estudo analisar o comportamento germinativo das sementes de Adenostemma brasilianum oriundas de população natural, avaliar sua qualidade física e verificar o seu tempo de embebição. Sementes foram coletadas em indivíduos de um fragmento de Floresta Estacional Semidecídua em Viçosa, Zona da Mata mineira, Sudeste brasileiro. Para avaliação da qualidade física, sementes recém-colhidas (zero mês) foram classificadas como perfeitas (escuras com embrião) ou imperfeitas (escuras ou claras, sem embrião). Amostras de 50 sementes recém-colhidas foram colocadas para germinar em três temperaturas $\left(20\right.$, 25 e $30^{\circ} \mathrm{C}$ ) e em três condições de luminosidade: com suplementação de luz (SUP), luz ambiente (AMB) e escuro contínuo (ESC). A germinação de sementes armazenadas por dois, quatro e seis meses foi testada utilizando-se metodologia idêntica. Sementes armazenadas por 12 e 18 meses foram colocadas para germinar a $25^{\circ} \mathrm{C}$ SUP. A dormência e a embebição foram testadas, respectivamente, com solução de tetrazólio e azul de metileno. Foram registradas $74,7 \%$ de sementes fisicamente perfeitas, e observou-se a partenocarpia (10\%). As sementes iniciaram a germinação ao oitavo dia após a semeadura. Os fatores luz, temperatura e armazenamento agiram sinergeticamente sobre a germinação das sementes. As maiores porcentagens médias de germinação foram observadas nas sementes recém-colhidas e submetidas às temperaturas de 25 e $30^{\circ} \mathrm{C}$ SUP, 85,5 e 88,5\%, respectivamente. A dormência das sementes foi constatada em baixa temperatura $\left(20^{\circ} \mathrm{C}\right)$, independentemente do tratamento de luz. $\mathrm{O}$ armazenamento aumentou a mortalidade e a quebra da dormência; aos 12 meses, a germinação foi nula. A absorção de água pela semente ocorreu 24 h após a sua imersão em solução de azul de metileno.
\end{abstract}

Palavras-chave: Dormência de semente, Fotoblastismo e Longevidade de semente.

\section{GERMINATION AND QUALITY OF Adenostemma brasilianum (PERS.) CASS. SEEDS, A NATIVE UNDERSTORE ASTERACEAE OF THE ATLANTIC FOREST}

\begin{abstract}
The objectives of this study were to analyze germinative behavior of Adenostemma brasilianum from natural population, to evaluate their physical quality and imbibition time. Seeds were collected from individuals in a semideciduous seasonal forest fragment in Viçosa, Zona da Mata of Minas Gerais State, in southeastern Brazil. For physical quality evaluation, newly collected seeds (month 0 ) were classified as perfect (dark seeds with embryo) or imperfect (dark or pale seeds without embryo). Samples of 50 newly collected seeds were germinated at three temperatures $\left(20,25\right.$ and $\left.30^{\circ} \mathrm{C}\right)$ and at three luminosity conditions: light supplementation (SUP), environment light (AMB) and continuous darkness (ESC). The germination of seed stored for two, four and six months was tested by utilizing the same methodology. Seeds stored for 12 and 18 months were germinated at $25^{\circ} \mathrm{C}$ SUP. Seed dormancy and imbibition were tested with tetrazolium solution and methylene blue stain, respectively. About $74.7 \%$ of the seeds were physically perfect and partenocarpy was observed (10\%).Seeds started to germinate on the eighth day after sowing. The factors light, temperature and storage acted synergistically on seed germination. The highest mean germination percentages were observed
\end{abstract}

\footnotetext{
${ }^{1}$ Recebido em 17.10.2009 e aceito para publicação em 31.10.2011.

${ }^{2}$ Programa de Pós-Graduação em Botânica pela Universidade Federal de Viçosa, UFV, Brasil. E-mail: <marianagodinhobot@gmail.com>.

${ }^{3}$ Departamento de Fitotecnia, Universidade Federal de Viçosa, UFV, Brasil. E-mail: <eveline@ufv.br>.

${ }^{4}$ Departamento de Biologia Vegetal, Universidade Federal de Viçosa, UFV, Brasil. E-mail: <mfvieira@ufv.br>.
} 
in newly collected seeds and submitted to temperatures of 25 and $30^{\circ} \mathrm{C}$ SUP (respectively 85.5 and $88.5 \%$ ). Seed dormancy was found in low temperature $\left(20^{\circ} \mathrm{C}\right)$, in presence or absence of light. Storage increased mortality and seed dormancy breakage; germination was null at 12 months. Water absorption by seeds occurred 24 hours after immersion in methylene blue solution.

Keywords: Photoblastism, Seed dormancy and Seed longevity.

\section{INTRODUÇÃO}

Adenostemma brasilianum é planta herbácea, anual e polinizada por borboletas (GODINHO, 2007). No Brasil, sua distribuição está restrita aos Estados do Sudeste, além de Santa Catarina e Rio Grande do Sul, quase sempre em formações florestais (MORAES, 1997). É conhecida por produzir alcaloide pirrolidizínico secretado juntamente com o néctar das flores (BROWN JR., 1984ab; TRIGO et al., 1996). Esse alcaloide é precursor da rota biossintética de feromônios de borboletas (Nymphalidae) e mariposas (Arctiidae), sendo fundamental na complementação do ciclo de vida desses insetos, além de lhes conferir impalatabilidade, defendendo-os contra predadores (BROWN JR., 1984ab; TRIGO et al., 1996; PAIVA; BARATA, 2004).

Estudos sobre a germinação das sementes de espécies de Asteraceae têm sido realizados por diversos autores (HILTON, 1983; PEREZ GARCIA, 1993; SEILER, 1996; VELTEN; GARCIA, 2005). Alguns autores avaliaram a influência de fatores ambientais, como luz e temperatura, sobre a porcentagem de germinação (HILTON, 1983; PEREZ GARCIA, 1993; SEILER, 1996; VELTEN e GARCIA, 2005). Outros abordaram a indução e quebra de dormência das sementes e a formação do banco de sementes (GUARIGUATA, 1988; GARCIA; SHARIF, 1995; SEILER, 1996; VELTEN, 2004). No Brasil, onde ocorrem cerca de 2.000 espécies (SOUZA; LORENZI, 2008), os estudos sobre germinação ainda são incipientes. Como exemplos, citam-se os de Figueredo (1975), Cordazzo e Souza (1993), Maluf e Wizentier (1998), Sassaki et al. (1999), Ferreira et al. (2001), Cordazzo e Spanó (2002) e Gomes e Fernandes (2002), além de alguns dos mencionados anteriormente.

O processo de germinação das sementes é complexo e sofre influência de diversos fatores ambientais, entre eles a luz, a temperatura, a umidade e os gases atmosféricos (MAYER; POLJAKOFF-MAYBER, 1979). Efeitos da luz e da temperatura na germinação de sementes de plantas nativas são comumente analisados (p. ex. SILVA et al., 2002; LIMAS et al., 2007). Esses efeitos podem ser avaliados a partir de mudanças ocasionadas na porcentagem, velocidade e frequência relativa de germinação, ao longo do tempo de incubação (LABOURIAU; PACHECO, 1978). Entretanto, uma incapacidade da semente em germinar pode ocorrer mesmo quando existem condições externas favoráveis, caracterizando a dormência (AMEN, 1968).

A dormência das sementes é considerada estratégia evolutiva importante para o sucesso reprodutivo de muitos vegetais, visto que distribui a germinação por dado período de tempo, mantendo as sementes viáveis, tornando irregular ou bloqueando a germinação em condições desfavoráveis à futura planta. Desse modo, são maiores as chances de as sementes germinarem em condições ambientais favoráveis e de desenvolverem-se em plantas adultas (AMEN, 1968; GILL; BLACKLOW, 1985). Além disso, ficam ampliadas as possibilidades de dispersão de sementes em longas distâncias, antes que iniciem o processo de germinação (SEILER, 1996).

Considerando a importância dos estudos de germinação para a propagação, regeneração e conservação florestal, o objetivo deste trabalho foi analisar o comportamento germinativo das sementes de A. brasilianum oriundas de população natural, para estabelecer as condições ótimas de germinação, visando ao manejo da espécie e ao seu cultivo, principalmente em borboletários. Além disso, foi avaliada a qualidade física das sementes e verificado o tempo gasto para que ocorra a embebição.

\section{MATERIAL E MÉTODOS}

\subsection{Local de amostragem, teste de qualidade $e$ preparação das sementes para germinação}

A pesquisa foi desenvolvida entre março de 2005 e setembro de 2006, utilizando-se sementes de $A$. brasilianum coletadas no maior fragmento florestal do município de Viçosa (194 ha), a Estação de Pesquisa, Treinamento e Educação Ambiental Mata do Paraíso (MP, 2048’07"S, 4251’31"W), que pertence à Universidade Federal de Viçosa. A vegetação da MP pertence aos domínios da Floresta Atlântica 
(RIZZINI, 1997) e é classificada como Floresta Estacional Semidecídua (VELOSO et al., 1991). Na MP, os indivíduos de $A$. brasilianum ocorrem em diversas trilhas e em parte da estrada principal de acesso, em áreas de sub-bosque parcialmente sombreadas. O material-testemunho encontra-se depositado no Herbário VIC (no. 29.191).

Para avaliação da qualidade física, foram coletadas sementes de cinco capítulos de cinco diferentes indivíduos, escolhidos aleatoriamente. Registraram-se as porcentagens de sementes perfeitas (escura e com embrião) e de sementes imperfeitas (escura ou clara, sem embrião), dissecando-as sob microscópio estereoscópico.

Sementes de outros capítulos foram coletadas e contadas. Posteriormente, foram analisadas sob microscópio estereoscópico, separando-se as morfologicamente perfeitas das imperfeitas, com base na coloração da semente (escura ou clara), sem avaliar a presença de embrião, para evitar danos à germinação. Uma porção das perfeitas foi utilizada imediatamente para os testes de germinação (sementes recém-colhidas), e as demais foram armazenadas em sacos de papel por 2, 4, 6, 12 e 18 meses, a $20^{\circ} \mathrm{C}$, para avaliações posteriores.

\subsection{Germinação e embebição das sementes}

Amostras de 50 sementes recém-colhidas foram colocadas para germinar em caixas plásticas (“gerbox”), em quatro repetições, sobre camada tripla de substrato (papel-filtro - germitest), embebido com água destilada na proporção de 3,5 vezes o peso do papel e mantidas em germinadores Mangelsdorff. Quando necessário, adicionou-se água para manter o papel úmido.

As sementes foram submetidas a três diferentes temperaturas $\left(20,25\right.$ e $\left.30^{\circ} \mathrm{C}\right)$ e três regimes de luz: com suplementação de luz fluorescente, fria e branca (BRASIL, 2009) e fotoperíodo de $8 \mathrm{~h}$ (SUP); luz ambiente (AMB), ou seja, iluminação da sala de germinação, sem suplementação de luz fluorescente; e escuro contínuo (ESC). Nesta última condição, para não haver entrada de luz, as caixas foram envolvidas com camada dupla de papel-alumínio e só foram abertas uma vez, para a contagem final.

As avaliações da germinação foram diárias (exceto na condição ESC), durante 27 dias consecutivos (até a estabilização da germinação), quando eram retiradas as plântulas normais, ou seja, com raiz primária, hipocótilo e cotilédones completamente expandidos. Nas condições SUP e AMB, foi também calculada a velocidade de germinação (VG), conforme sugerido por Vieira e Carvalho (1994):

$V G=\left(G_{1 X} N_{1)}+\left(G_{2 X} N_{2}\right)+\ldots+\left(G_{n X} N_{n}\right) / G_{1}+G_{2}\right.$ $+\ldots+\mathrm{Gn}$, em que $\mathrm{VG}=$ velocidade de germinação; $\mathrm{G}_{1,2} \cdots_{\mathrm{n}}$ número de plântulas normais retiradas do experimento a cada dia de análise; $\mathrm{e}_{1,2 \ldots \mathrm{n}}=$ número de dias decorridos da semeadura até a respectiva contagem.

Ao finalizarem os testes, as sementes não germinadas foram contadas e observadas em microscópio estereoscópico, para verificar a presença ou ausência do embrião. Todas as sementes que continham embrião e que não haviam germinado foram testadas quanto à viabilidade, para verificar a presença de dormência, utilizando-se solução de tetrazólio a $0,075 \%$ por, aproximadamente, $1 \mathrm{~h}$, a $25^{\circ} \mathrm{C}$. Os embriões com coloração rósea foram considerados dormentes, e os que não se coraram foram considerados mortos.

A germinação das sementes armazenadas por dois, quatro e seis meses foi testada submetendo-as às mesmas condições descritas anteriormente para as sementes recém-colhidas. A germinação das sementes armazenadas por 12 e 18 meses foi testada na condição de $25{ }^{\circ} \mathrm{C}$ SUP.

O tempo gasto para a embebição foi verificado em sementes imersas em solução de azul de metileno 0,1\% (SHELDON, 1974), por 12 e 24 h. Posteriormente, foram cortadas longitudinalmente com lâmina de barbear e observadas em microscópio estereoscópico.

\subsection{Análise estatística}

O experimento foi instalado em delineamento inteiramente casualizado com quatro repetições. Adotou-se um esquema de parcelas subdivididas, empregando o fatorial $3 \times 3$ (3 temperaturas $\times 3$ regimes de luminosidade) na parcela e quatro tempos de armazenamento (0, 2, 4 e 6 meses) nas subparcelas. Os dados foram transformados em arcosseno, mas apresentados destransformados (em porcentagem) nas tabelas. Em todos os testes aplicados, os pressupostos foram observados e cumpridos conforme Zar (1999); o teste de Tukey foi utilizado a 5\% de significância.

Revista Árvore, Viçosa-MG, v.35, n.6, p.1197-1205, 2011 


\section{RESULTADOS}

Foram encontradas em média, por capítulo, $31( \pm 7,6)$ sementes. Das 787 sementes analisadas, 74,7\% eram perfeitas. Entre as imperfeitas, cerca de 10\% apresentavam-se aparentemente perfeitas (escuras), embora desprovidas de embrião, caracterizando a partenocarpia.

Os resultados dos testes de germinação de sementes recém-colhidas e armazenadas (2, 4e 6 meses) encontram-se na Tabela 1. As sementes armazenadas por 12 e 18 meses não germinaram, e o teste com tetrazólio indicou que estavam mortas.

As maiores porcentagens de germinação foram observadas nas sementes recém-colhidas e submetidas às temperaturas de 25 e $30^{\circ} \mathrm{C}$ SUP. Nessas condições, obtiveram-se, respectivamente, 85,5 e 88,5\%, valores esses que não diferiram estatisticamente, conforme o teste de Tukey (Tabela 1). Nas demais condições de luz e temperatura e em todos os tempos de armazenamento,

Tabela 1 - Porcentagens médias de germinação de sementes de Adenostemma brasilianum, submetidas a diferentes condições: temperaturas $(20,25$ e $30{ }^{\circ} \mathrm{C}$ ), regimes de luminosidade (SUP $=$ luz suplementar, AMB = luz ambiente e ESC = escuro) e tempos de armazenamento (0, 2, 4 e 6 meses).

Table 1 -Average germination percentage of Adenostemma brasilianum seeds submitted to different conditions: temperatures $\left(20,25\right.$ and $\left.30^{\circ} \mathrm{C}\right)$, light $(S U P=$ supplementary light, $A M B=$ environment light and ESC = darkness) and storage times $(0,2,4$ and 6 months) .

\begin{tabular}{ccccc}
\hline Condições & \multicolumn{5}{c}{ Tempo de armazenamento em meses } \\
\cline { 2 - 5 } & 0 & 2 & 4 & 6 \\
\hline \multicolumn{5}{c}{ SUP } \\
\hline $20^{\circ}$ & $16,5 \mathrm{Ba}$ & $17,5 \mathrm{Aa}$ & $09,0 \mathrm{Bab}$ & $04,0 \mathrm{Bb}$ \\
$25^{\circ}$ & $85,5 \mathrm{Aa}$ & $46,0 \mathrm{Aab}$ & $73,0 \mathrm{Aab}$ & $25,0 \mathrm{Ab}$ \\
$30^{\circ}$ & $88,5 \mathrm{Aa}$ & $25,0 \mathrm{Ab}$ & $33,5 \mathrm{Aab}$ & $20,5 \mathrm{Ab}$ \\
\hline \multicolumn{5}{c}{$\mathrm{AMB}$} \\
\hline $20^{\circ}$ & $00,0 \mathrm{Bb}$ & $00,0 \mathrm{Bb}$ & $08,5 \mathrm{Aa}$ & $01,5 \mathrm{Bb}$ \\
$25^{\circ}$ & $11,0 \mathrm{Aab}$ & $01,5 \mathrm{Bc}$ & $22,0 \mathrm{Aa}$ & $06,0 \mathrm{Bb}$ \\
$30^{\circ}$ & $00,5 \mathrm{Bb}$ & $15,0 \mathrm{Aa}$ & $11,5 \mathrm{Aa}$ & $13,0 \mathrm{Aa}$ \\
\hline \multicolumn{5}{c}{$\mathrm{ESC}$} \\
\hline $20^{\circ}$ & $00,0 \mathrm{Ba}$ & $00,0 \mathrm{Ba}$ & $00,5 \mathrm{Ba}$ & $00,0 \mathrm{Ba}$ \\
$25^{\circ}$ & $13,0 \mathrm{Aa}$ & $10,0 \mathrm{Aab}$ & $05,4 \mathrm{Aab}$ & $04,5 \mathrm{Ab}$ \\
$30^{\circ}$ & $04,5 \mathrm{Aa}$ & $00,0 \mathrm{Bb}$ & $00,0 \mathrm{Bb}$ & $00,0 \mathrm{Bb}$ \\
\hline
\end{tabular}

Letras maiúsculas correspondem a comparações em uma mesma coluna e minúsculas na linha. Letras iguais correspondem a valores estatisticamente iguais, conforme o teste de Tukey para $\mathrm{p}=0,05$.

Revista Árvore, Viçosa-MG, v.35, n.6, p.1197-1205, 2011 as porcentagens de germinação foram inferiores ou iguais a $46 \%$, exceto a $25^{\circ} \mathrm{C}$ SUP, em sementes armazenadas por quatro meses (73\% - Tabela 1 e Figura 1$)$.

A análise de variância evidenciou que os fatores luz, temperatura e tempo de armazenamento agem simultaneamente sobre a germinação de $A$. brasilianum $(\mathrm{F}=8.29$; g.l. $=12 ; \mathrm{P}<0,0001)$. Entretanto, quando submetidas às variadas condições de temperatura e de tempos de armazenamento, as sementes que receberam luz suplementar (SUP) atingiram porcentagens de germinação superiores às submetidas aos dois outros regimes de luminosidade (AMB e ESC) (Tabela 1 e Figura 1).

Houve a tendência de as sementes testadas a $20^{\circ} \mathrm{C}$ AMB e ESC, em todos os tempos de armazenamento, apresentarem germinação nula ou baixa ( $\leq 8,5 \%)$; nas demais temperaturas, as germinações foram baixas ( $\leq 22 \%)$ ou também nulas (Tabela 1 e Figura 1$)$.

A partir do oitavo dia após a semeadura, observaram-se as primeiras sementes germinadas, e o processo de desenvolvimento da plântula durou de dois a três dias. O início da germinação foi caracterizado pelo rompimento do pericarpo, na região próxima ao carpopódio, e pelo desenvolvimento da raiz primária, que se apresentou alongada e pouco

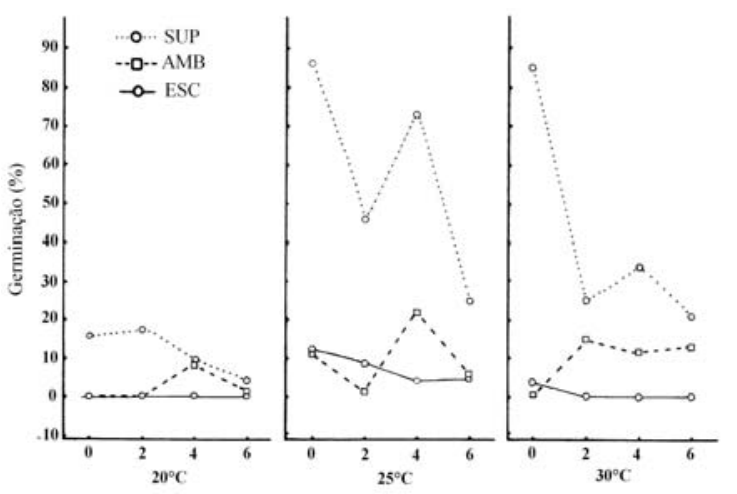

Figura 1 - Representação gráfica do efeito das diferentes condições: temperatura $\left(20,25\right.$ e $\left.30{ }^{\circ} \mathrm{C}\right)$, regime de luminosidade (SUP = luz suplementar, AMB = luz ambiente e ESC = escuro) e tempo de armazenamento (0, 2, 4 e 6 meses) sobre a porcentagem de germinação em sementes de Adenostemma brasilianum.

Figure 1 - Graphical representation of the effect of different conditions: temperature $\left(20,25\right.$ and $\left.30^{\circ} \mathrm{C}\right)$, light $(S U P=$ supplementary light, $A M B=$ environment light and ESC = darkness) and storage time $(0,2,4$ and 6 months), on the germination percentage of Adenostemma brasilianum seeds. 
sinuosa. Os pêlos absorventes desenvolveram-se antes da queda do pericarpo. Com isso, ocorreram a exposição dos cotilédones e a expansão do hipocótilo. Os cotilédones expostos rapidamente adquiriram coloração verde e, em seguida, expandiram-se totalmente; nessa ocasião, ocorreu o crescimento da raiz primária.

A velocidade e início da germinação das sementes (Tabela 2) não apresentaram clara tendência de queda ou aumento, em relação às variáveis analisadas (tempos de armazenamento, temperaturas e regimes de luminosidade). Entretanto, os resultados da Tabela 2 confirmaram aqueles apresentados na Tabela 1, ou seja, as melhores condições de germinação foram: sementes recém-colhidas e submetidas a $25{ }^{\circ} \mathrm{C}$ SUP. Nessas condições foram obtidas sementes vigorosas e germinadas ao oitavo dia (Tabela 2).

As porcentagens de sementes sem embrião (partenocarpia) (Tabela 3), como era de se esperar, não apresentaram relação com as condições de temperatura, regime de luz e tempo de armazenamento. Houve tendência de aumento da mortalidade e da quebra da dormência, ao longo do tempo de armazenamento (Tabela 3). As sementes na condição ESC apresentaram as maiores taxas de dormência (Tabela 3).
As sementes, após $24 \mathrm{~h}$ em solução de azul de metileno, exibiram grande extensão do embrião corada de azul, inclusive os cotilédones, indicando que houve embebição.

Tabela 2 - Velocidade de germinação (VG) e início da germinação (IG), em números médios de dias, resultantes dos experimentos de germinação em Adenostemma brasilianum, em sementes submetidas a diferentes condições: temperatura $\left(20,25\right.$ e $30^{\circ} \mathrm{C}$ ), regimes de luminosidade (SUP = luz suplementar e $\mathrm{AMB}=$ luz ambiente) e tempo de armazenamento (0, 2, 4 e 6 meses).

Table 2 - Germination velocity (GV) and germination start (GS) in average number of days resulting from the germination experiments in Adenostemma brasilianum seeds submitted to different conditions: temperature $\left(20,25\right.$ and $\left.30^{\circ} \mathrm{C}\right)$, light (SUP = supplementary light and $A M B=$ environment light) and storage time (0, 2, 4 and 6 months).

\begin{tabular}{|c|c|c|c|c|c|c|c|c|}
\hline \multirow[t]{2}{*}{ Condições } & \multicolumn{4}{|c|}{ VG (dias) } & \multicolumn{4}{|c|}{ IG (dias) } \\
\hline & 0 & 2 & 4 & $\overline{6}$ & 0 & 2 & 4 & 6 \\
\hline \multicolumn{9}{|c|}{ SUP } \\
\hline $20^{\circ}$ & 20 & 19 & 22 & 22 & 14 & 12 & 17 & 13 \\
\hline $25^{\circ}$ & 15 & 17 & 17 & 20 & 8 & 8 & 12 & 12 \\
\hline $30^{\circ}$ & 19 & 14 & 19 & 19 & 12 & 9 & 14 & 14 \\
\hline \multicolumn{9}{|c|}{ AMB } \\
\hline $20^{\circ}$ & - & - & 23 & 18 & - & - & 18 & 19 \\
\hline $25^{\circ}$ & 23 & 22 & 17 & 19 & 20 & 20 & 12 & 1 \\
\hline $30^{\circ}$ & 24 & 22 & 16 & 24 & 24 & 15 & 14 & 15 \\
\hline
\end{tabular}

Tabela 3 - Porcentagens médias de sementes sem embrião (SE), mortas (SM) e dormentes (SD) observadas ao final dos experimentos de germinação em Adenostemma brasilianum, em sementes submetidas a diferentes condições: temperatura $\left(20,25\right.$ e $\left.30^{\circ} \mathrm{C}\right)$, regimes de luminosidade (SUP = luz suplementar, AMB = luz ambiente e ESC = escuro) e tempo de armazenamento (0, 2, 4 e 6 meses).

Table 3 - Average percentages of seeds without embryo (SE), dead (SM) and dormant (SD) observed at the end of the germination experiments in Adenostemma brasilianum seeds submitted to different conditions: temperature (20, 25 and $\left.30^{\circ} \mathrm{C}\right)$, light $(S U P=$ supplementary light, $A M B=$ environment light and $E S C=$ darkness $)$ and storage time $(0,2,4$ and 6 months).

\begin{tabular}{|c|c|c|c|c|c|c|c|c|c|c|c|c|}
\hline \multirow[t]{2}{*}{ Condições } & \multicolumn{4}{|c|}{ SE (\%) } & \multicolumn{4}{|c|}{ SM (\%) } & \multicolumn{4}{|c|}{ SD (\%) } \\
\hline & 0 & 2 & 4 & 6 & 0 & 2 & 4 & 6 & 0 & 2 & 4 & 6 \\
\hline \multicolumn{13}{|c|}{ SUP } \\
\hline $20^{\circ}$ & 00,0 & 02,0 & 00,3 & 02,0 & 02,0 & 03,0 & 11,5 & 37,0 & 39,8 & 36,3 & 34,3 & 08,5 \\
\hline $25^{\circ}$ & 02,8 & 04,0 & 07,5 & 06,5 & 03,0 & 07,0 & 03,1 & 24,8 & 01,5 & 16,0 & 02,8 & 09,1 \\
\hline $30^{\circ}$ & 03,8 & 13,3 & 08,8 & 04,4 & 01,0 & 07,3 & 06,5 & 27,4 & 02,0 & 17,0 & 18,0 & 08,0 \\
\hline \multicolumn{13}{|c|}{ AMB } \\
\hline $20^{\circ}$ & 01,0 & 10,3 & 01,8 & 02,8 & 13,3 & 02,8 & 17,0 & 25,2 & 35,8 & 37,0 & 26,4 & 21,0 \\
\hline $25^{\circ}$ & 00,8 & 10,5 & 01,8 & 05,8 & 24,0 & 28,3 & 15,8 & 23,5 & 19,8 & 31,7 & 21,5 & 17,3 \\
\hline $30^{\circ}$ & 01,0 & 15,0 & 03,0 & 01,5 & 26,4 & 34,0 & 12,4 & 26,5 & 23,4 & 19,2 & 28,8 & 16,1 \\
\hline \multicolumn{13}{|c|}{ ESC } \\
\hline $20^{\circ}$ & 01,8 & 01,5 & 02,8 & 01,8 & 03,5 & 07,5 & 05,8 & 22,3 & 44,6 & 41,5 & 42,1 & 27,0 \\
\hline $25^{\circ}$ & 00,8 & 03,3 & 06,5 & 03,0 & 01,5 & 03,0 & 19,0 & 20,9 & 42,3 & 36,5 & 22,0 & 22,3 \\
\hline $30^{\circ}$ & 00,5 & 07,3 & 03,6 & 03,4 & 07,5 & 17,0 & 30,5 & 35,8 & 39,6 & 25,8 & 16,3 & 11,2 \\
\hline
\end{tabular}




\section{DISCUSSÃO}

A porcentagem de sementes perfeitas $(74,7 \%) \mathrm{em}$ A. brasilianum foi maior que a obtida em outras espécies de Asteraceae por Maluf e Wizentier (1998) e Velten (2004), que registraram valores variando de 50 a $70 \%$. Esses autores também verificaram a partenocarpia. Não havendo como separar visualmente as sementes escuras imperfeitas (partenocarpia) das perfeitas devido à semelhança morfológica, as imperfeitas também foram inseridas nos testes de germinação, influenciando negativamente os resultados apresentados neste trabalho.

A germinação das sementes de A. brasilianum, iniciada ao oitavo dia, foi rápida. Essa rapidez é estratégia para um pronto estabelecimento das plântulas, em condições ambientais favoráveis, além de ser um bom índice para avaliar a capacidade de ocupação de um ambiente (ver FERREIRA et al., 2001). A dispersão dos diásporos dessa espécie ocorre na estação chuvosa (GODINHO, 2007), período com condições climáticas ideais para germinação (elevadas temperaturas e precipitações). A pronta germinação das sementes inviabiliza a formação de um banco de sementes, assim como sua curta longevidade (inferior a 12 meses). No entanto, observou-se a formação de banco de plântulas de $A$. brasilianum, que persistiu por oito meses (de março a outubro - GODINHO, 2007).

Velten (2004) estudou a morfologia das sementes de três espécies de Eremanthus e observou, utilizando o azul de metileno, que a embebição iniciou-se na região basal da semente, também conhecida como carpopódio, e foi completa após $24 \mathrm{~h}$. Esses resultados assemelham-se aos obtidos em A. brasilianum.

As porcentagens de germinação das sementes recém-colhidas de $A$. brasilianum, nas melhores condições de luminosidade e temperatura, foram altas (85,5 e 88,5\%), especialmente se comparadas às porcentagens comumente registradas na família. Lawrence (1980) estudou 36 espécies de Senecio, e apenas 18 delas apresentaram porcentagens de germinação superiores a 85\%. Ferreira et al. (2001) estudaram sementes de 13 espécies, de vários gêneros, e apenas quatro mostraram porcentagens de germinação superiores a 50\%. As baixas porcentagens de germinação têm sido explicadas pelo requerimento de condições ambientais específicas (LAWRENCE, 1980) ou como reflexo dos elevados percentuais de sementes sem embrião, difíceis de serem eliminadas dos experimentos por se apresentarem morfologicamente perfeitas (FIGUEREDO, 1975; CLAMPITT, 1987; MALUF; WIZENTIER, 1998; FERREIRA et al., 2001; este estudo).

Apesar de os três fatores avaliados terem influenciado na germinação das sementes de $A$. brasilianum, a luminosidade suplementar (SUP) foi fator relevante que resultou em altas porcentagens de germinação e pareceu ser essencial para a superação da dormência. O fotoblastismo positivo é muito comum entre as asteráceas (BASKIN; BASKIN, 1979; GRIME et al., 1981; LADEIRA et al., 1987; MALUF; WIZENTIER, 1998; FERREIRA et al., 2001; VELTEN; GARCIA, 2005), e os resultados deste estudo confirmaram essa tendência.

Sheldon (1974) comentou que o fotoblastismo positivo, em espécies de Asteraceae, é uma adaptação positiva, pois na família predominam sementes pequenas e com reservas escassas. Segundo esse autor, essas sementes, expostas à luz e sobre o solo, germinam imediatamente, e as plântulas podem iniciar seu estádio autotrófico; o estabelecimento dos indivíduos, portanto, dependerá de menos reserva da semente.

Além dos regimes de luminosidade, condições ideais de temperatura resultaram em maiores porcentagens de germinação em $A$. brasilianum, semelhante ao registrado em outras espécies de Asteraceae (FIGUEREDO, 1975; FORSYTHeBROWN, 1980; GRIME et al., 1981; BORGHTTI et al., 2002). Grime et al. (1981), por exemplo, observaram que a germinação de 41 , das 45 espécies estudadas, foi favorecida por temperaturas superiores a $25^{\circ} \mathrm{C}$, tal como verificado em $A$. brasilianum. Reddy e Singh (1992) mencionaram que a temperatura age determinando mudanças no estado físico dos componentes celulares das sementes de Bidens pilosa, que aceleram as reações internas e proporcionam altas porcentagens de germinação.

A tendência do aumento da mortalidade e da quebra de dormência das sementes de A. brasilianum, ao longo do tempo de armazenamento, é característica observada também em outras espécies de Asteraceae (CORDAZZO; SOUZA, 1993; CORDAZZO; SPANÓ, 2002; GOMES; FERNANDES, 2002). Gomes e Fernandes (2002) observaram relação direta entre o aumento da mortalidade de sementes de Baccharis dracunculifolia e o seu envelhecimento; após um ano de armazenamento, menos de $30 \%$ das sementes germinaram, ao passo que as recém-coletadas apresentavam germinação superior a $75 \%$. 
A curta longevidade das sementes $A$. brasilianum, inferior a 12 meses, pareceu ser característica incomum em ervas anuais, considerando os estudos de Grime et al. (1981). Esses autores estudaram a germinação de 403 espécies de ervas anuais, constatando que havia tendência à pronta germinação; entretanto, as sementes remanescentes no solo permaneceram vivas por longos períodos. Os resultados deste estudo indicaram que a estratégia reprodutiva de $A$. brasilianum diferiu das espécies estudadas por esses autores, visto que apresentou rápida germinação e formou um banco de plântulas (GODINHO, 2007), mas não sobreviveu ao armazenamento.

A irregularidade da germinação das sementes de A. brasilianum, ao longo dos seis meses de armazenamento e nas diferentes condições de luz e temperatura, parece estar relacionada à sua rusticidade como planta silvestre. Em praticamente todas as condições testadas, as sementes apresentaram alguma germinação, mesmo que em pequenas porcentagens, caracterizando elevada plasticidade germinativa. Essa plasticidade deve gerar consequências ecológicas úteis, favorecendo a manutenção da espécie em populações naturais.

\section{CONCLUSÕES}

Adenostemma brasilianum produz cerca de $75 \%$ de sementes perfeitas, ou seja, com coloração escura e embrião.

As sementes iniciam a germinação no oitavo dia após a semeadura, e o processo de desenvolvimento da plântula dura de dois a três dias.

A absorção de água pela semente se completa em $24 \mathrm{~h}$.

As maiores porcentagens de germinação (> 85\%) foram observadas em sementes recém-colhidas e submetidas às temperaturas de 25 e $30^{\circ} \mathrm{C}$ com luz suplementar, caracterizando fotoblastismo positivo.

A $20^{\circ} \mathrm{C}$, independentemente da luminosidade, a dormência das sementes é induzida.

A viabilidade das sementes decresce com o armazenamento; após 12 meses, não germinam.

\section{AGRADECIMENTOS}

À Fundação de Amparo à Pesquisa do Estado de Minas Gerais (FAPEMIG), pela bolsa concedida à primeira autora; ao CNPq, pela bolsa de produtividade concedida à terceira autora; e ao Departamento de Engenharia Florestal da Universidade Federal de Viçosa, por permitir os estudos na "Mata do Paraíso".

\section{REFERÊNCIAS}

AMEN, R. D. A model of seed dormancy. Botanical Review, v.34, p.1-31, 1968.

BASKIN, J. M.; BASKIN, C. C. The germination strategy of oldfield Aster (Aster pilosus).

American Journal of Botany, v.66, n.1, p.1-5, 1979.

BORGHTTI, F.; NODA, F. N. \& MARTINS, C. S. A. Possible involvement of proteasome activity in ethylene-induced germination of dormant sunflower embryos. Brazilian Journal

Plant Physiology, v.14, n.1, p.125-131, 2002.

BRASIL. Ministério da Agricultura, Pecuária e Abastecimento. Secretaria de Defesa

Agropecuária. Regras para análise de sementes. Brasília: 2009.

BROWN JR., K. S. Adult-obtained pyrrolidizine alkaloids defend Ithomiinae butterflies against a spider predator. Nature, v.309, p.707-709, 1984a.

BROWN JR., K. S. Chemical ecology of dehydropyrrolizidine alkaloids in adult Ithomiinae (Lepdoptera: Nymphalidae). Revista Brasileira de Biologia, v. 44, n.4, p. 435460, 1984b.

CLAMPITT, C. A. Reproductive biology of Aster curtus (Asteraceae), a pacific northwest endemic. American Journal of Botany, v.74, n.6, p.941-946, 1987.

CORDAZZO, C. V.; SOUZA, C. V. Germinação de Senecio crassiflorus (Compositae). Revista Brasileira de Biologia, v.53, n.1, p.81-86, 1993.

CORDAZZO, C. V.; SPANÓ, S. Produção e germinação de sementes de Senecio crassiflorus (Poir.) DC (Asteraceae), coletadas ao longo de um gradiente nas dunas costeiras do sul do Brasil. Atlântica, v.24, n.1, p.11-15, 2002.

FERREIRA, A. G. et al. Germinação de sementes de Asteraceae nativas no Rio Grande do Sul, Brasil. Acta Botanica Brasílica, v.15, n.2, p.231-242, 2001.

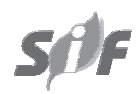

Revista Árvore, Viçosa-MG, v.35, n.6, p.1197-1205, 2011 
FIGUEREDO, R. C. Notas preliminares sobre a germinação e ocorrência de derivados cumarínicos em aquênios de Eupatorium pauciflorum H.B.K. (Compositae). Hoehnea, v.5, n.1, p.57-57, 1975.

FORSYTH, C.; BROWN, N. A. C. Germination of the dimorphic fruits of Bidens piolosa L. New Phytologist, v.90, n.1, p.151-164, 1980.

GARCIA, Q. S.; SHARIF, R. R. Germinação e dormência de aquênios de Achantospermum hispidum DC, uma espécie invasora.

Revista Brasileira de Botânica, v.18, n.1, p.17-25, 1995.

GILL, G. S.; BLACKLOW, W. M. Variations in seed dormancy and rates of development of great brome, Bromus diandrus Roth, as adaptations to the climates of southern Australia and implications for weed control. Australian Journal of Agricultural Research, v.36, n.2, p.295-304, 1985.

GODINHO, M. A. S. Biologia reprodutiva e germinação de sementes em Adenostemma brasilianum (Pers.) Cass.

(Asteraceae). 2007. Dissertação (Mestrado em Botânica) - Universidade Federal de Viçosa, Viçosa, MG, 2007.

GOMES, V.; FERNANDES, G. W. Germinação de aquênios de Baccharis dracunculifolia D.C.

(Asteraceae). Acta Botanica Brasílica, v.16, n.4, p.421-427, 2002.

GRIME, J. P. et al. A comparative study of germination characteristics in a local flora. Journal of Ecology, v.69, n.3, p.1017-1059, 1981.

GUARIGUATA, M. R. Seed bank dynamics and germination ecology in Espeletia timotensis (Compositae), an Andean Giant Rosette. Biotropica, v.20, n.1, p.54-59, 1988.

HILTON, J. R. The influence of light on the germination of Senecio vulgaris L. New Phytologist, v.94, n.1, p.29-37, 1983.

LABOURIAU, L. C.; PACHECO, A. On the frequency of isothermal germination in seeds of Dolichos biflorus L. Plant \& Cell Physiology, v.19, n.3, p.507-512, 1978.
LADEIRA, A. M.; ZAIDAN, L. B. P. \& FIGUEREDO-RIBEIRO, R. C. Ageratum conyzoides L. (Compositae): Germinação, floração e ocorrência de derivados fenólicos em diferentes estágios de desenvolvimento. Hoehnea, v.14, n.1, p.53-62, 1987.

LAWRENCE, M. E. Senecio L. (Asteraceae) in Australia: Reproductive biology of a genus found primarily in unstable environments. Australian Journal of Botany, v.33, n.2, p.197-208, 1980.

LIMAS, J. D.; SILVA, B. M. S. \& MORAES, W. S. Germinação e armazenamento de sementes de Virola surinamensis (Rol.) Warb. (Myristicaceae). Revista Árvore, v.31, n.1, p.37-42, 2007.

MALUF, A. M.; WIZENTIER, B. Aspectos fenológicos e germinação de sementes de quatro populações de Eupatorium vauthierianum DC. (Asteraceae). Revista Brasileira de Botânica, v.21, n.3, p.247-257, 1998.

MAYER, A. M.; POLJAKOFF-MAYBER, A. The germination of seeds. Oxford: Pergamon Press, 1979.

MORAES, M. D. A família Asteraceae na planície litorânea de Picinguaba município de Ubatuba-SP. 1997. Dissertação (Mestrado em Biologia Vegetal) - Universidade Estadual de Campinas, Campinas, SP, 1997.

PAIVA, J. A.; BARATA, L. E. S. Pirrolizidine alkaloids in three Senecio species from Southern Brazil. Biochemical Systematics and Ecology, v.32, n.12, p.1219-1222, 2004.

PEREZ GARCIA, F. Effect of the origin of the cypsela on germination of Onopordum acanthium L. ( Asteraceae). Seed Science \&

Techonology, v.21, n.1, p.187-195, 1993.

REDDY, K. N.; SINGH, M. Germination and emergence of hairy beggarticks (Bidens pilosa). Weed Science, v.40, n.1, p.195-199, 1992.

RIZZINI, C. T. Tratado de fitogeografia do Brasil: aspectos ecológicos, sociológicos e florísticos. Rio de Janeiro: Âmbito Cultural, 1997.

SASSAKI, R. M. et al. Germination of seeds from herbaceous plants artificially stored in cerrado soil. Revista Brasileira de Biologia, v.59, n.2, p.271-279, 1999. 
SEILER, G. J. Dormancy and germination of wild Helianthus species. In: CALIGARI, P. D. S.; HIND, D. J. N. (Eds.). Compositae: biology \& utilization. New York: Royal Botanical Gardens, 1996. p.213-222.

SHELDON, J. C. The behavior of seeds in soil. Journal of Ecology, v.62, n.1, p.47-66, 1974.

SILVA, L. M. M.; RODRIGUES, T. J. D.; AGUIAR, I. B. Efeito da luz e da temperatura na germinação de sementes de aroeira (Myracroduon urundeuva Allemão). Revista Árvore, v.26, n.6, p.691-697, 2002.

SOUZA, V. C.; LORENZI, H. Botânica sistemática - Guia ilustrado para identificação das famílias de fanerógamas nativas e exóticas no Brasil, baseado em APG II. Nova Odessa: Instituto Plantarum de Estudos da Flora, 2008.

TRIGO, J. R. et al. Qualitative patterns of pyrrolidizine alkaloids in Ithomiinae butterflies. Biochemical Systematic and Ecology, v.24, n.1, p.181-188, 1996.
VELOSO, H. P.; RANGEL-FILHO, A. L.; LIMA, J. C. A. Classificação da vegetação brasileira, adaptada a um sistema universal. Rio de Janeiro: Fundação Instituto Brasileiro de Geografia e Estatística, 1991.

VELTEN, S. B. Aspectos morfológicos dos aquênios, germinação e potencial de formação de banco de sementes de Eremanthus (Asteraceae), ocorrentes na Serra do Cipó, Minas Gerais. 2004. Dissertação (Mestrado em Biologia Vegetal) Universidade Federal de Minas Gerais, Belo Horizonte, MG, 2004.

VELTEN, S. B.; GARCIA, Q. S. Efeitos da luz e da temperatura na germinação de sementes de Eremanthus (Asteraceae), ocorrentes na Serra do Cipó, MG, Brasil. Acta Botanica Brasílica, v.19, n.4, p.753-761, 2005.

VIEIRA, R. D.; CARVALHO, N. M. Testes de vigor em sementes. Jaboticabal: FUNEP, 1994.

ZAR, J. H. Bioestatistical analysis. 4.ed. New Jersey: Prentice Hall International, 1999. 
